\title{
Bilinguale Lyrik eines Esslinger Humanisten
}

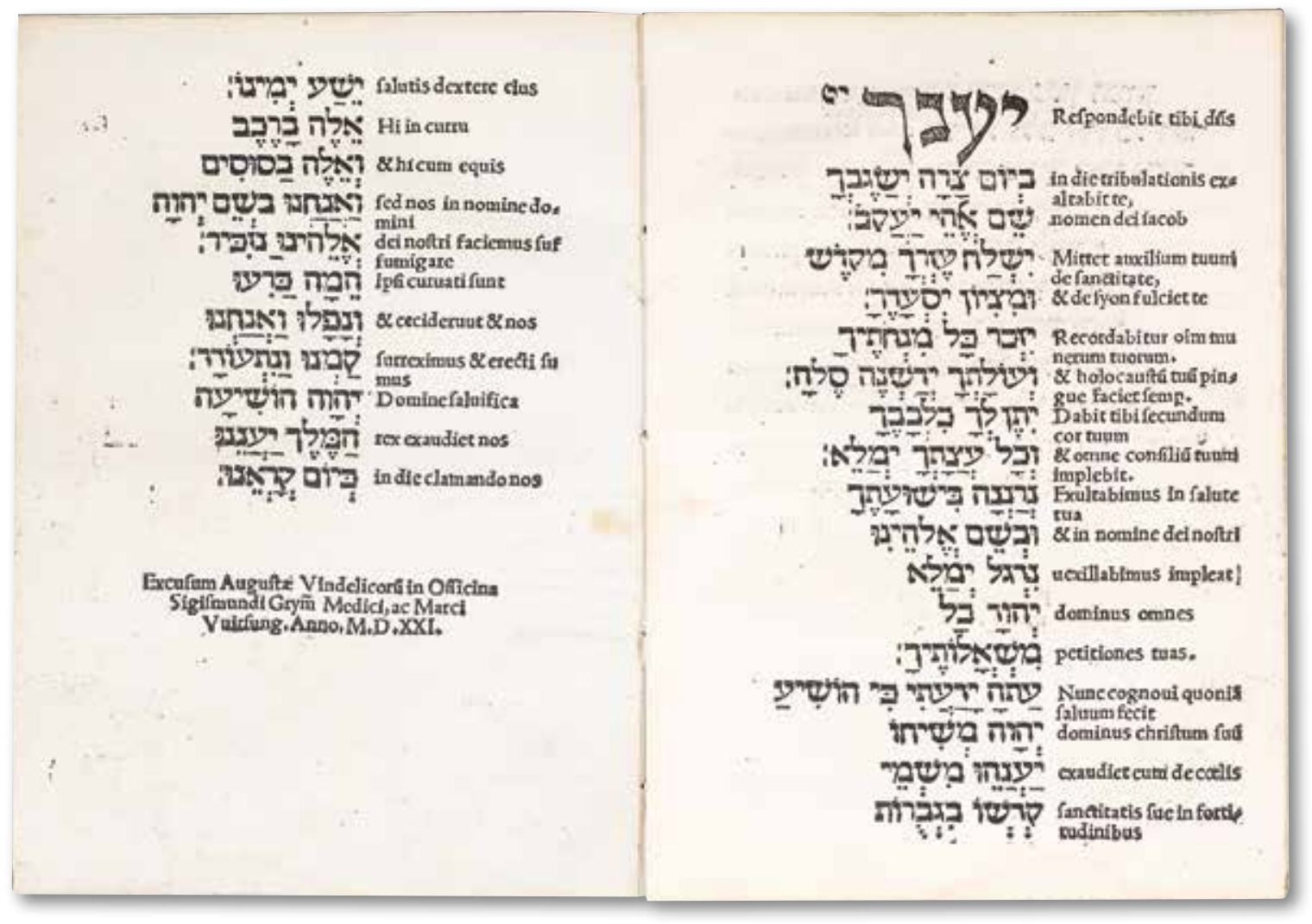

Abb.: HBF 10182: Bilingualer Psalm 20

Der Südwesten brachte mit Johannes Reuchlin (1455-1522) und Philipp Melanchthon (1497-1560) zwei der bekanntesten humanistischen Gelehrten hervor. Mit innen verband sich ein Netzwerk philologisch interessierter Personen. Gemeinsames Anliegen war der Rekurs zu den antiken Quellen („Ad fontes“), sowohl was die Philosophie als auch was insbesondere die Sprachen anging. Man wollte sich nicht mit dem eingeführten Latein als Wissenschaftssprache begnügen, sondern hinter die vorliegenden lateinischen Übersetzungen der griechischen Klassiker und der Bibel zurückgehen zu den Ursprachen. Auch die lateinischen Klassiker wurden neu gelesen und die Kenntnis des Lateinischen im Abgleich mit dem griechischen und bald darauf hebräischen Original geschärft.

Reuchlin war einer der Begründer der wissenschaftlichen Hebraistik. Das Hebräische wurde nun aus philologischen Gründen ebenfalls von Nichtjuden erlernt und erforscht. Zu den Schülern
Reuchlins gehörte Johann Böschenstein (14721540) aus Esslingen. Melanchthon stand in engem Austausch mit den südwestdeutschen Humanistenzirkeln und wurde auf den zunächst in Ingolstadt tätigen Böschenstein aufmerksam. Es ist sicher Melanchthon zu verdanken, dass Böschenstein im Jahr 1518 auf einen Lehrstuhl für Hebraistik an der Universität Wittenberg berufen wurde. Reformation und Humanismus berührten sich in dem Streben nach einer exakten Kenntnis der ursprachlichen Texte der Bibel und nach einer entsprechenden Sprachkompetenz der Bibelausleger. Allerdings wollte Luther dadurch eine möglichst authentische Bibellektüre ermöglichen, weil auf der Wechselwirkung von Wort Gottes und Glauben das gesamte System der reformatorischen Theologie basiert. Dabei war der buchstäbliche Sinn der Bibel in philologischer Präzision grundlegend. Den Humanisten war dagegen über den theologischen Nutzen hinaus an der Erforschung und Einübung der klassischen Sprachen an sich gelegen. We- 
gen der abweichenden Zielsetzung und der ungenügenden Bezahlung seiner Tätigkeit verließ Böschenstein Wittenberg nach einem Semester wieder und war als Lehrer tätig.

Die vorliegende, 1521 bei Sigmund Grimm und Marx Wirsung in Augsburg gedruckte Schrift (HBF 10182) veranschaulicht den souveränen, geradezu spielerischen Umgang des humanistischen Gelehrten mit den alten Sprachen. Nach einer Widmungsvorrede an den katholischen Bischof von Wien, Georg von Slatkonia (1456-1522), sind drei lyrische Texte in zwei Kolumnen in lateinischer und hebräischer Fassung so abgedruckt, dass die poetische Struktur erkennbar ist. Böschenstein formulierte ein mariologisches Gebet („Precatio ad divam virginem matrem domini “) und übertrug es ins Hebräische. Darauf folgt im acht Blatt umfassenden Druck ein jüdisches Bekenntnis, das als Sündenbekenntnis gegenüber dem Gott der Väter ("Deus patrum nostrorum“) gestaltet ist. Am Ende steht der Psalm 20 mit punktierter hebräischer Schrift und einer darauf basierenden Neuübersetzung ins Lateinische. Der traditionelle Text der lateinischen Vulgata weicht deutlich davon ab.

Der Druck des südwestdeutschen Hebraisten ergänzt gut den Bestand humanistischer Schriften in der WLB und die beiden vorhandenen Drucke Böschensteins.

Christian Herrmann

\section{Bedeutende Ergänzung der Bibelsammlung}

Die Bibelsammlung der Württembergischen Landesbibliothek stellt in ihrer Zusammensetzung eine unschätzbare Quelle für theologische, philologische und buchgeschichtliche Forschungen dar. Dies betrifft einerseits den älteren Teil des Bestandes. Dort ist vor allem der buchgeschichtliche Weg der Ausgaben mit ihren Beigaben, ihrer Typographie sowie ihrer Ausstattung mit Illustrationen und Einbänden bis hin zu besonderen Provenienzen

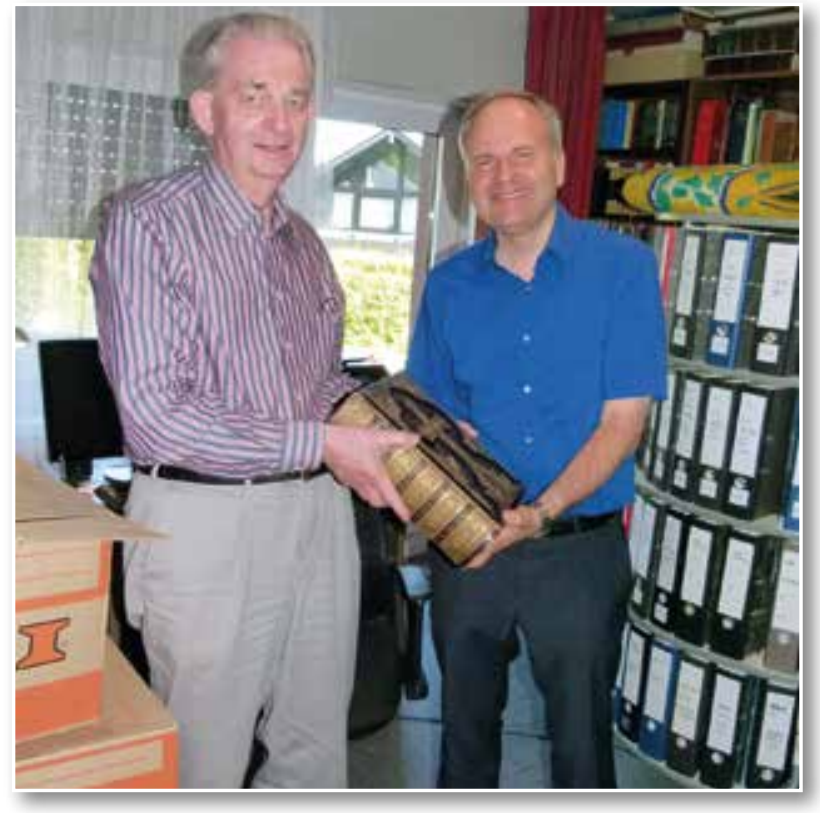

Abb.: Übergabe der Bibelsammlung durch Professor Thesing von Interesse. Auch waren zahlreiche Bibeln die ersten gedruckten Bücher überhaupt in einer bestimmten Sprache.

Andererseits bietet die Bibelsammlung in ihrem neueren Teil mehr als im älteren eine einzigartige Vielfalt an Sprachen und Übersetzungen. Die ersten Missionare waren zunächst Sprachforscher und nutzten die Sprachkenntnisse für die Übersetzung der Bibel. Für Sprachen, die nur von wenigen Menschen gesprochen werden, hält die Pionierforschung von Missionsgesellschaften bis heute an. In größeren Sprachkreisen kommt es zu neuen und verbesserten Ausgaben. Für vergleichende Sprachstudien, aber auch als philologische Primärquelle der Literatur einer bestimmten Sprache und als Anhaltspunkt für die Missions- und Kirchengeschichte sind Bibelausgaben insbesondere außereuropäischer Länder gut geeignet.

Das Segment der außereuropäischen Sprachen in der Bibelsammlung hat im August 2016 eine bedeutende Ergänzung erfahren. Auch mit Unterstützung der Württembergischen Bibliotheksgesellschaft gelang es, einen großen Teil einer privaten Bibelsammlung zu erwerben. Prof. Dr. Josef Thesing, Königswinter, zuletzt stellvertretender Generalsekretär der Konrad-Adenauer-Stiftung, 